\section{Coming Events}

Due to COVID-19, please check to see if the listed events have been postponed or canceled.

\section{1}

\section{ABRF 2021}

March 7-10, 2021

Boston, MA

https://web.cvent.com/event/8eb4a085-b3c5-464aba49-023f033a7ee $4 /$ summary?Refld=ABRF\%20

$2021 \% 20$ Annual\%20Meeting\%2OHome

Focus on Microscopy 2021

March 28-31, 2021

Porto, Portugal

www.focusonmicroscopy.org

EMAS 2021 - 17th European Workshop on Modern Developments and

Applications in Microbeam Analysis

May 16-20, 2021

Krakow, Poland

www.microbeamanalysis.eu/events/event/60-

emas-2021-17th-european-workshop-on-modern-

developments-and-applications-in-microbeam-analysis

IUMAS-8: 8th Meeting of the

International Union of Microbeam

Analysis Societies

May 24-28, 2021

Banff, Alberta, Canada

www.microbeamanalysis.eu/events/event/

74-iumas-8-8th-meeting-of-the-international-

union-of-microbeam- analysis-societies

mmc2021: Microscience Microscopy

Congress 2021

July 5-8, 2021

Manchester, UK

www.mmc-series.org.uk

Microscopy \& Microanalysis 2021

August 1-5, 2021

Pittsburgh, PA

www.microscopy.org/events/future.cfm

2022

Microscopy \& Microanalysis 2022

July 31-August 4, 2022

Portland, OR

www.microscopy.org/events/future.cfm

2023

Microscopy \& Microanalysis 2023

July 24-28, 2023

Minneapolis, MN

www.microscopy.org/events/future.cfm

\section{4}

Microscopy \& Microanalysis 2024

July 28-August 1, 2024

Cleveland, $\mathrm{OH}$

www.microscopy.org/events/future.cfm

\title{
Splitting Hairs Under the Microscope
}

\author{
Stephen W. Carmichael \\ Mayo Clinic, Rochester, MN 55905 \\ carmichael.stephen@mayo.edu
}

The existence of sharp objects created by humankind dates back millenia in the archeological record. Utensils, weapons, and other blades have been a part of human history and are essential in many aspects of our lives today. Although the specific requirements for sharp objects are varied, the overall material design is constant: achieving high sharpness and hardness. However, even the hardened stainless steel in a razor blade, coated with a diamond-containing material to make it even harder, loses its functionality when cutting a much softer material such as human hair just a few times. Kitchen knives, also, get dull when cutting soft substances such as cheese or potatoes. It is common to resharpen knives to make them fully functional again, which leads to the general conception that wear mechanisms are responsible for the performance degradation of sharp metallic edges. Essentially, a sharp edge wears to a more round shape, and the sharp edge can be restored by applying an abrasive at the proper angle (honing). A recent study by Gianluca Roscioli, Seyedeh Mohadeseh Taheri-Mousavi, and Cemal Cem Tasan showed that simple wear is not the only mechanism by which metal edges become dull when cutting hair; but rather an entirely different mechanism is largely responsible for this phenomenon.

Although wear does occur during hair cutting, the failure mechanisms are more complex for two reasons. First, the structure of steel and hair are very different. Steel has heterogeneous internal features (Figure 1) that result in high hardness but a nonuniform micromechanical response. Hair is softer by more than an order of magnitude. Hair has an outer cuticle enclosing softer material with a hollow center. The different structure of hair results in a mechanical response in the steel that depends on several factors that contribute to deformation of the steel. Second, a hair is flexible resulting in different volumes of the hair interacting with the steel during different stages of cutting, which contributes to deformation of both materials.

The first step was to examine disposable razor blades by scanning electron microscopy (SEM). Roscioli et al. quantified the blade wear rate along the sharp edge during hair cutting using image analysis. The level of wear was low. However, they observed chips along the sharp edge. Certain features of the fracture surface of the chips indicated that the edge deformed before fracture. To better understand the development of this failure process, they performed SEM tests using a microdeformation stage with customized clamps that could hold a blade on one side and a single or multiple hair(s) on the other. Running in situ SEM tests enabled investigation of the underlying damage mechanisms. When the blade was perpendicular to the hair, the blade did not deform or chip. By contrast, creating a more realistic condition by tilting the blade created an out-of-plane force component and, in turn, led to plastic deformation and chipping. They also discovered that the chips most commonly appeared when the edge encountered the outer cuticle of the hair shaft. For example, one single hair could produce two chips in the blade, each of them corresponding to an edge of the hair.

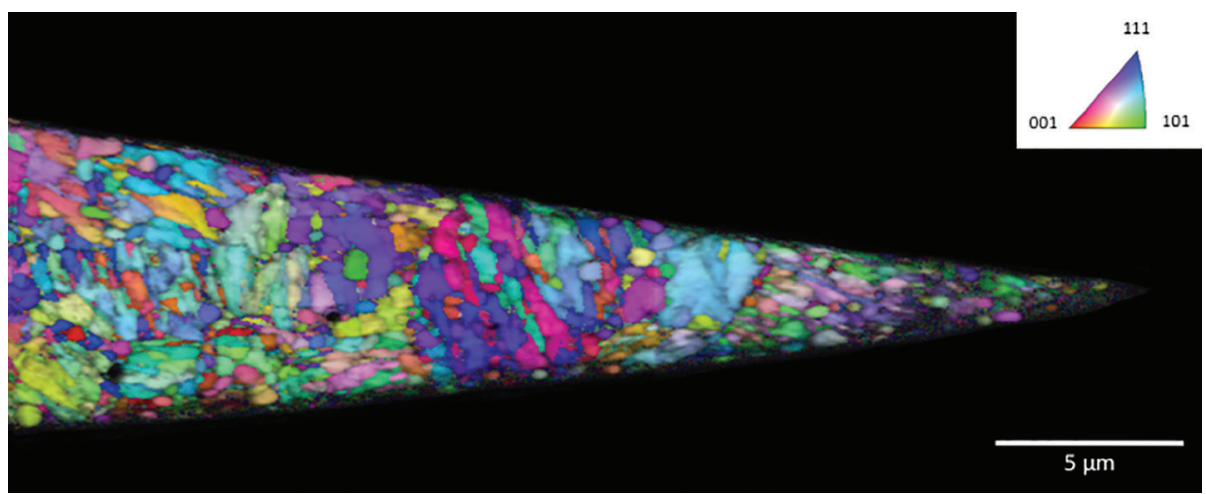

Figure 1: Cross section of a razor blade. Electron backscatter diffraction inverse pole figure map of a cross section of a commercial razor blade. The blade shows a lath martensitic microstructure, with no preferential orientation, and a deformed surface layer due to the honing process on both sides of the sharp edge. The deformed layers merge at the tip of the razor blade in a region with higher grain boundary density. 


\section{First $\gg \gg\rangle$}

\section{HIGH THROUGHPUT SEM System}

\section{Navigator-10}

(6) 10 times faster than

conventional FE SEMs

(7) Direct electron detection technology and

Dual channel imaging (SE\&BSE)

Intelligent atlas and cross-scale

material characterization

(๔) Big data intelligent analysis and Al computing
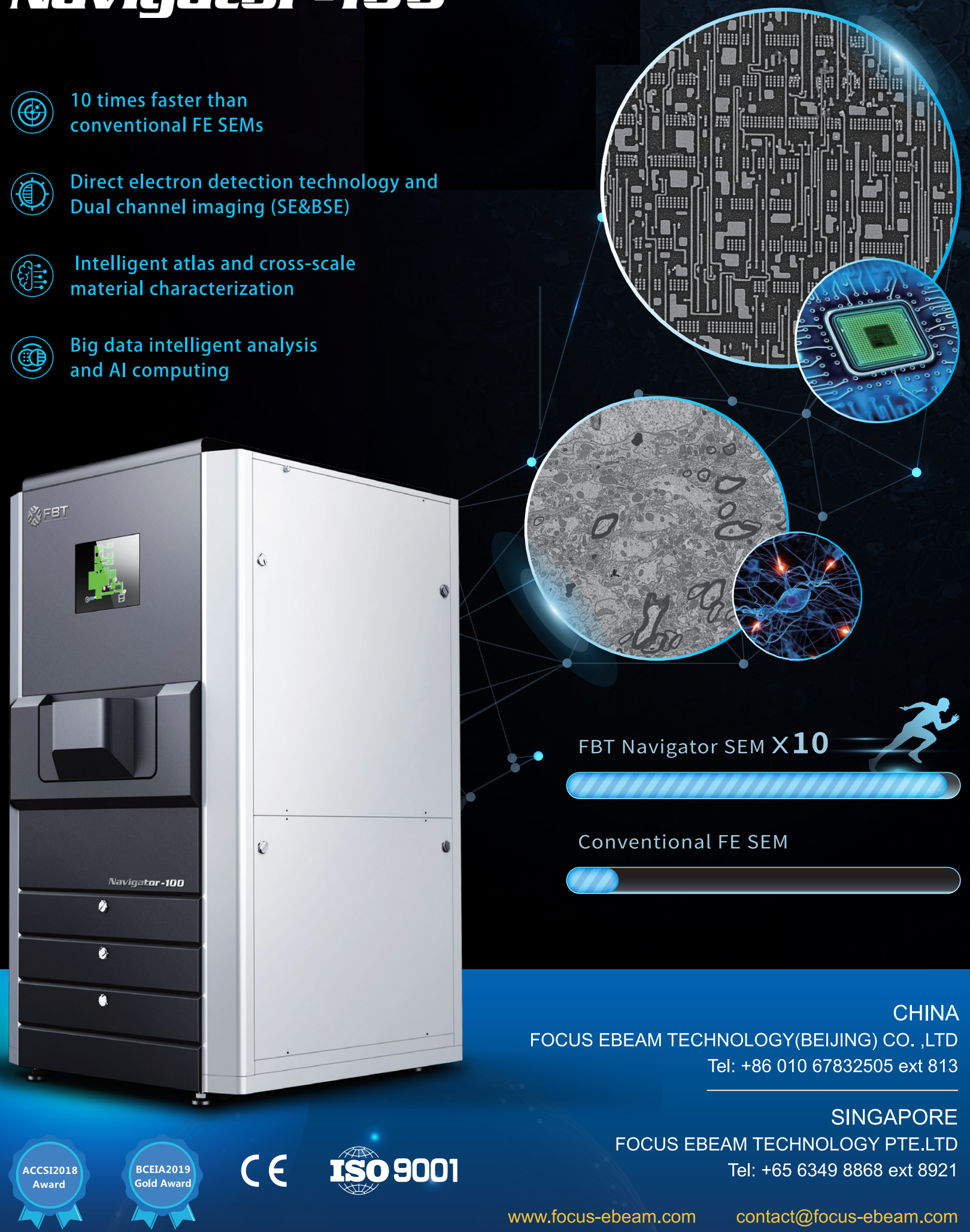

CHINA

FOCUS EBEAM TECHNOLOGY(BEIJING) CO. ,LTD

Tel: +86 01067832505 ext 813

SINGAPORE

FOCUS EBEAM TECHNOLOGY PTE.LTD

Tel: +65 63498868 ext 8921 
In Situ Tensile \& Compression from micro Newtons to $10 \mathrm{kN}$.

\section{Kammrath \& Weiss $\mathrm{GmbH}$

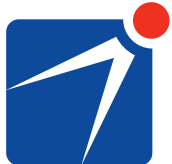

Quality Made in Germany since 1995.

New York, USA

Dortmund, Germany

Mail: sales@kammrath-weiss.com

Phone: +1 516-313-9742

www.kammrath-weiss.com

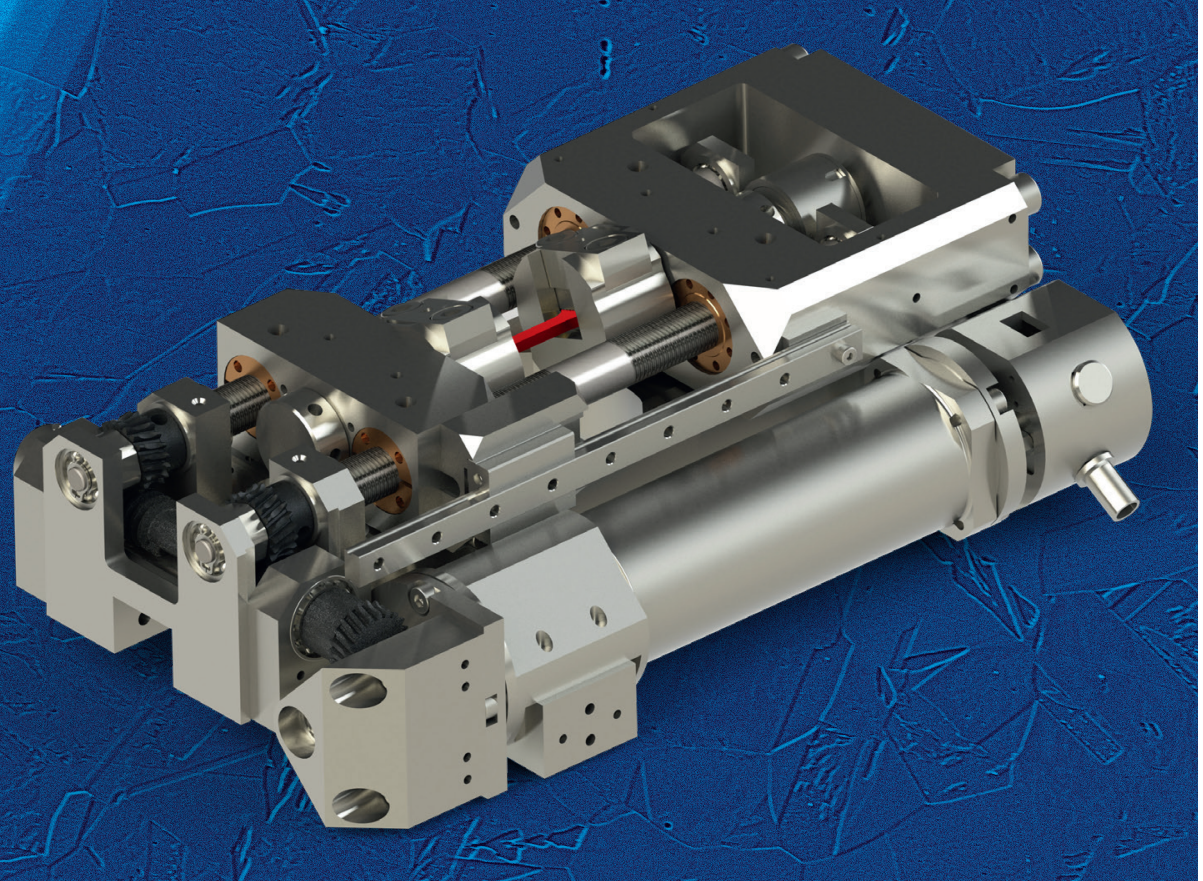

Roscioli et al. performed several additional analyses, including simulations, that led them to the conclusion that haircutting causes structural failure at the edge of the blade when the hair was pushed into a (relatively) softer region bordered by a harder region within the steel. The stress on this boundary initiated a series of events that resulted in a fracture of the blade (chipping). Therefore, chipping occurs before other proposed failure modes due to wear effects or brittleness of the hard coatings.

It was apparent that the mechanism of chipping was revealed only by in situ observation during the cutting process. Static SEM analysis would not have told the whole story. The dynamic imaging of a hair interacting with the razor's edge in this elegant study was the key to demonstrating deformation of the steel and subsequent chipping. These and other insights suggested that more homogeneous microstructures for cutting tools could allow for more durable sharp edges. The ability to produce more efficient and longer-lasting sharp edges would have a favorable environmental impact by extending material functional duration. This, in turn, could motivate further investigations that would reduce waste and improve our environment.

\section{References}

[1] Roscioli et al., Science 369 (2020) 689-94. DOI:10.1126/ science.aba9490

[2] The author gratefully acknowledges Dr. Cemal Cem Tasan for reviewing this article and Dr. Gianluca Roscioli for supplying the image.

\section{SEM Scintillators \& Light Guides} Light Guide Recoating Services too!

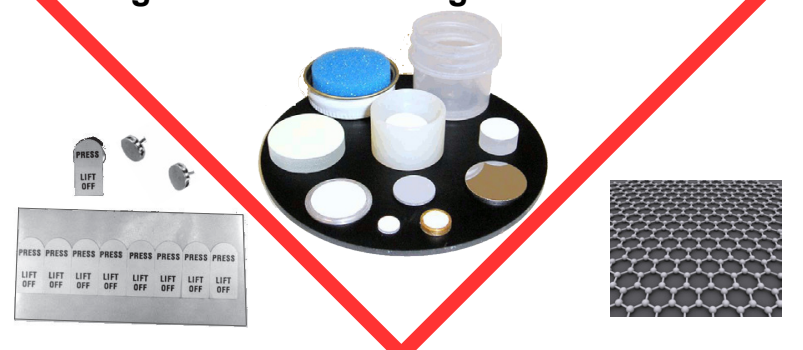

Conductive Adhesives, Introducing GRAPHENE Coatings \& Tabs!

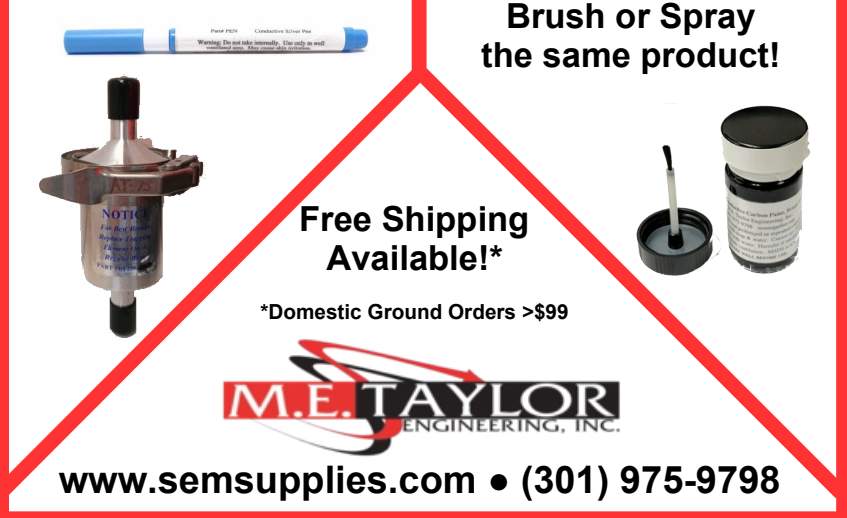




\section{IITESCAN}

\section{Field-free analytical UHR SEM}

\section{for materials characterization}

\section{at the nanoscale}

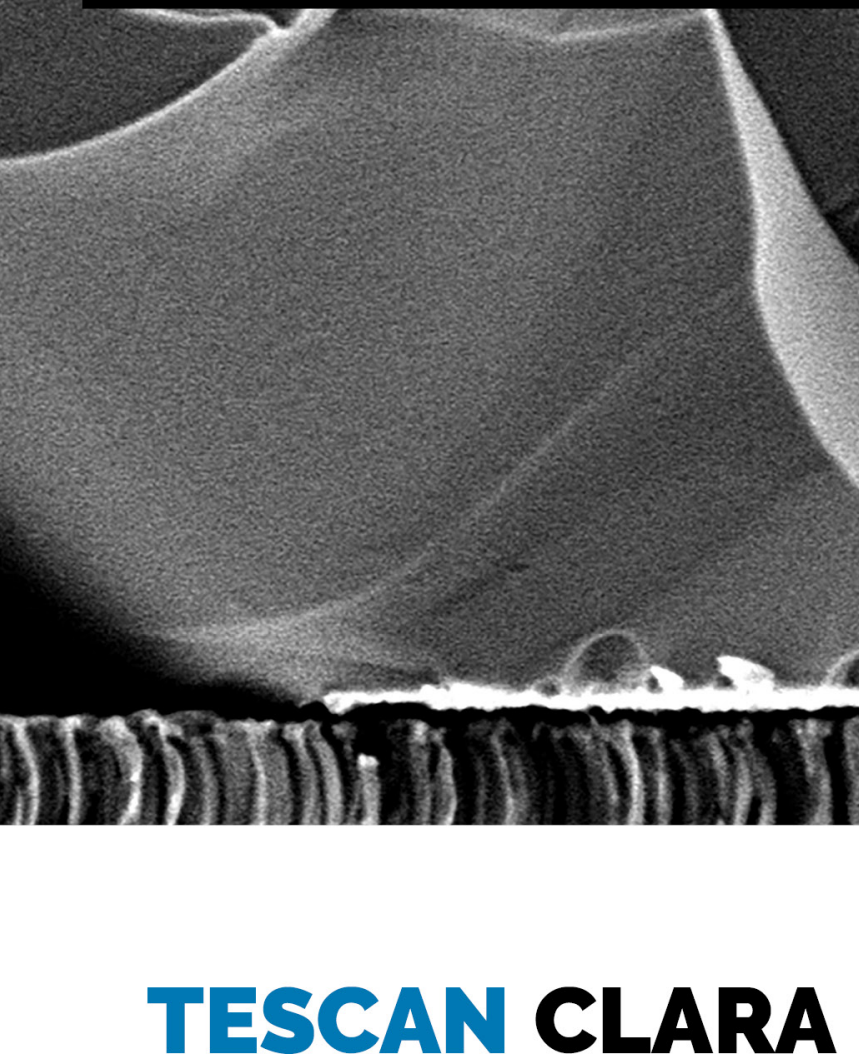

$\checkmark$ Unique BSE contrast discrimination based on BSEs take off angle and energy, using advanced in column Multidetector design

$\checkmark$ UHR topographical characterization of materials at low beam energies in field-free fashion using Bright Beam ${ }^{\text {tw }}$ technology

$\checkmark$ Excellent for imaging beam-sensitive and non-conductive samples

$\checkmark$ Fast setup of electron beam - optimal imaging and analytical conditions guaranteed by In-Flight Beam Tracing ${ }^{\text {TI }}$

$\checkmark$ Intuitive and precise live-SEM navigation on the sample at low magnification without the need for an optical navigation camera

$\checkmark$ Effortless operation regardless of a user's experience level guaranteed by intuitive Essence ${ }^{\text {th }}$ software

$\checkmark$ Ultimate topographical nanocharacterization at low landing voltages delivered by combination of BrightBeam ${ }^{\text {Tw }}$ Technology and optional Beam Deceleration Technology

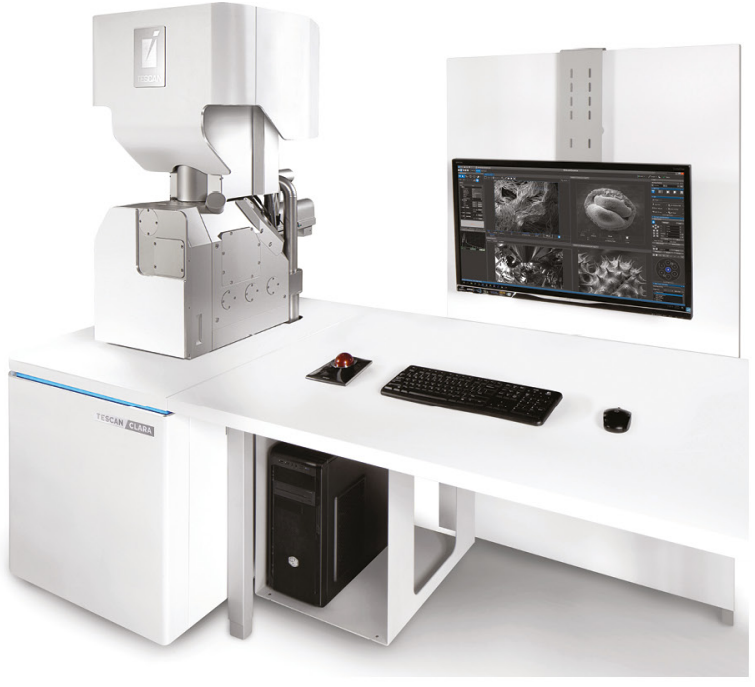

For more information visit 